\title{
Experimental investigation of artificial intelligence applied in MPPT techniques
}

\author{
S. Della Krachai ${ }^{1,4}$, A. Boudghene Stambouli ${ }^{2}$, M. Della Krachai ${ }^{3}$, M. Bekhti ${ }^{4}$ \\ ${ }^{1,2,3}$ Department of Electronics, University of Science and Technologies - Mohamed Boudiaf, Algeria \\ ${ }^{4}$ Spatial Development Center, Algeria
}

\begin{tabular}{l} 
Article Info \\
\hline Article history: \\
Received Mar 17, 2019 \\
Revised Apr 14, 2019 \\
Accepted May 28, 2019 \\
\hline Keywords: \\
Adaptive neural fuzzy inference \\
systems \\
Artificial intelligence \\
Hardware in the loop \\
Neural networks \\
Synchronous buck converter
\end{tabular}

\begin{abstract}
Nano-satellites are key features for sharing the space data and scientific researches. They embed subsystems that are fed from solar panels and batteries. Power generated from these panels is subject to environmental conditions, most important of them are irradiance and temperature. Optimizing the usage of this power versus environmental variations is a primary task. Synchronous DC-DC buck converter is used to control the power transferred from PV panels to the subsystems while maintaining operation at maximal power. In this paper, artificial intelligence techniques: neural networks and adaptive neural fuzzy inference systems (ANFIS) are used to accomplish the tracking task. Simulation and experimental results demonstrate their efficiency, robustness and tracking quality.
\end{abstract}

Copyright (C) 2019 Institute of Advanced Engineering and Science. All rights reserved.

\section{Corresponding Author:}

S. Della Krachai,

Department of Electronics, Electrical Engineering Faculty,

University of Science and Technologies - Mohamed Boudiaf,

El Mnaouar, BP1505, Bir El Djir 31000, Oran, Algeria.

Email: saidia.dellakrachai@univ-usto.dz

\section{INTRODUCTION}

Power management in a satellite is a mandatory task. The overall power is consumed from PV panels which exhibits non-linear characteristics depending on theenvironmental conditions. These has a considerable impact on the maximal generated power. To optimize the efficiency of the supply system, extracting the maximal power is realized trough controllers called Maximal Power Point Trackers.

Several techniques and methods have been proposed for tracking the maximal powergenerated by PV panels. The traditional solutions proposed for these trackers are Hill climbing [1], Perturb and Observe [2-5] and Incrementalconductance methods [6]. These methods present an oscillation problem around the maximal power point as a drawback, however, they are light and easy to implement.

Other solutions are based on artificial intelligence techniques such as fuzzy logic [7-9], ant colony optimization [10], and neural networks [11-14]. These techniques improve considerably the efficiency of the system; however, implementation of these algorithms require more computations and coding.

In this paper, the online application of artificial intelligence techniques: neural networks and fuzzy logic is investigated through simulation and hardware in the loop experimentation using a low-cost solution. This approach allows not only maximizing the system efficiency, but also gives the opportunity to adjust the parameters online in order to meet the desired requirements and shorten the time to market delivery.

\section{CHARACTERISTICS OF PV PANEL IN USE}

Each PV panel consists of a set of series connected cells to produce considerable amount of voltage. The main outputs we are interested in are $\mathrm{I}-\mathrm{V}$ and $\mathrm{P}-\mathrm{V}$ curves which reveal three important points. Short- 
circuit current $\left(\mathrm{I}_{\mathrm{sc}}\right)$ at which the output voltage is null, open-circuit voltage $\left(\mathrm{V}_{\mathrm{oc}}\right)$ at which no output current is produced and the $\mathrm{P}_{\max }$ point at which the panel operates at its maximal efficiency.

The PV panel used ET-M53675 is from ET-Solar company (Table 1).

Table 1. ET-M53675 PV panel back-sheet data at $1000 \mathrm{w} / \mathrm{m}^{2}, 25^{\circ} \mathrm{C}$

\begin{tabular}{cc}
\hline Parameter & Value \\
\hline Power at MP- Pm(W) & 75 \\
Open circuit voltage - Voc (V) & 21.73 \\
Short-circuit current Isc (A) & 4.7 \\
Voltage at MPP - Vm (V) & 17.41 \\
Current at Mpp - Im (A) & 4.31 \\
\hline
\end{tabular}

The impact of irradiance and temperature on the output produced current and power is given in Figure 1. An increase in temperature involves a decrease in open-circuit voltage and consequently the maximal power. In contrary, an increase in irradiance implies an increase in a short-circuit current and consequently an increase in maximal power.
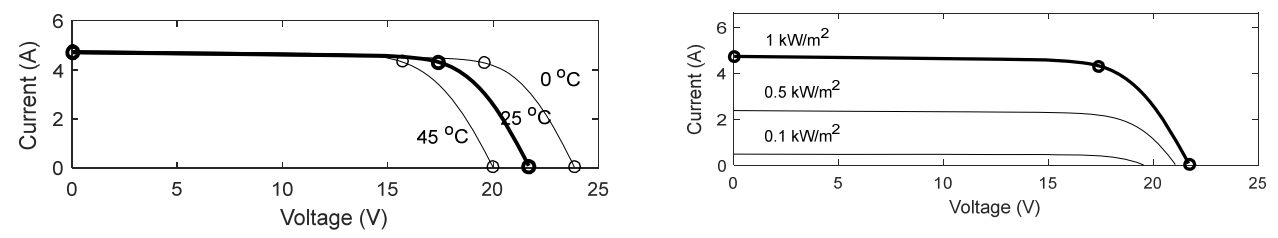

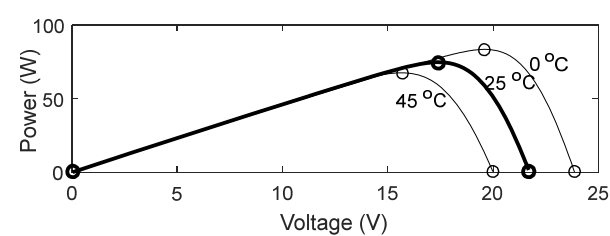

(a)

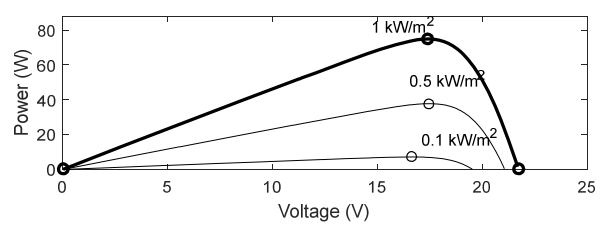

(b)

Figure 1. (a) Temperature and (b) Irradiance influence on PV panel characteristics

From the above remarks, the panel must be kept operating at its maximal power even if irradiance and temperature change. This is usually ensured by a device called MPPT: maximal power point tracker. Aritificial intelligence is used to accomplish this task.

\section{NEURAL NETWORK MPPT}

Neural networks are qualified as a universal approximators [15], they can mimic every complex function. They are used to model unknown systems behaviour using a set of input-output data and a training process. Neural networks are formalized using a cascaded layers interconnexion. Each layer consists of a set of neurons. Increasing the number of layers and neurons leads to best representation of non-linearities of the system, however, it exhibits complex computations, and therefore, hardware implementation constraints.

In this paper they are used to mimic the MPPT functionality. An experimental database comprising irradiance $\left(\mathrm{E}_{\mathrm{s}}\right)$, temperature $(\mathrm{T})$ and maximal output voltage $\left(\mathrm{V}_{\mathrm{mpp}}\right)$ at MPP have been collected and prepared for training and validation process. These inputs are measured, filtered and normalized.

The number of hidden layers and neurons inside them have been subjected to an optimization procedure based on observing the mean square error at the end of training process. It has been decided to adopt the architecture that comprises one hidden layer with five (5) neurons (Figure 2) which gives satisfactory precision.

The training process is carried out using Levenberg-Marquardt Algorithm [16]. The database was partitioned as follows:

- Training data : 70\% of dataset

- Validation data : $15 \%$ of dataset

- Testing data : $15 \%$ of dataset

Experimental investigation of artificial intelligence applied in MPPT techniques (S. Della Krachai) 
Figure 3 gives four plots, issued at the end of the training process. The overall performance is satisfactory, which proves that the network has been trained correctly and reflects with high fidelity the inputoutput relationship. The resultant network is used in simulation and experimental benchmark.

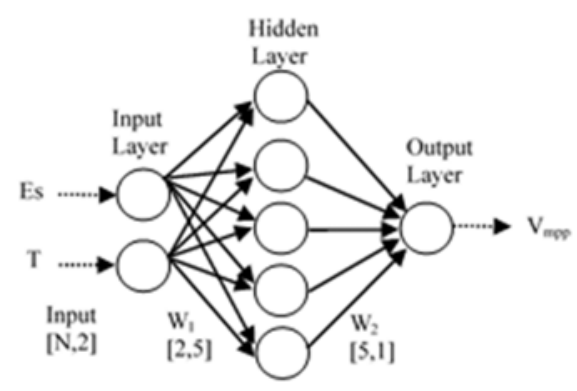

Figure 2. Neural network proposed composition
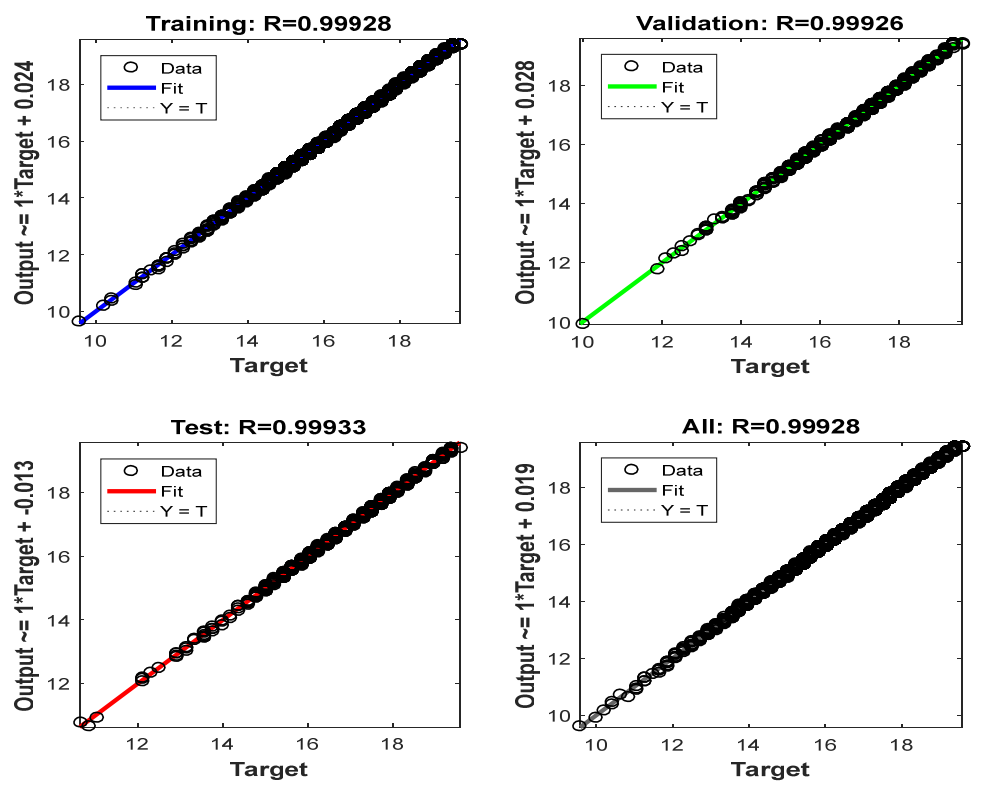

Figure 3. Neural network performance plots

\section{FUZZY MPPT-ANFIS APPROACH}

Fuzzy logic [17] is used to describe the operation of a process through a human reasoning language. Inputs of the process are first converted to fuzzy space using a universe of discourse and membership functions (fuzzification). A set of if-then rules are inferred to give a decision based on the present inputs. A fuzzy output is produced as a consequence. This output is then converted to real world value through defuzzification.

In this paper we have used adaptive neural fuzzy inference systems [18] to generate a fuzzy system that operates as an MPP tracker using the same training data set from the previous section. ANFIS (Figure 4) is build around a layered architecture, in which each layer implements a dedicated function.

Layer 1: Each square node in this layer computes the function

$$
O_{i}^{1}=\mu_{A_{i}}(x)
$$


where $x$ is the input to node $i$, and $A_{i}$ is the linguistic label associated with this node. $O_{i}^{1}$ is the membership degree of $A_{i}$

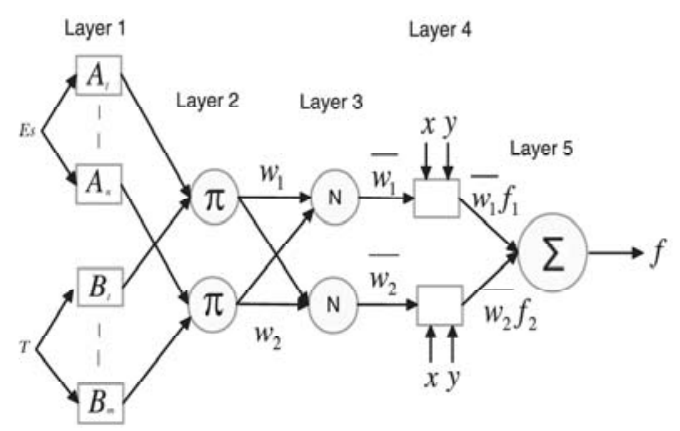

Figure 4. ANFIS architecture used to produce Fuzzy MPP Tracker

Layer 2: Every circle node in this layer computes the product of incoming signals.

$$
\omega_{i}=\mu_{A_{i}}(x) \times \mu_{B_{i}}(y)
$$

This represents the firing strength of the rule.

Layer 3: Every circle node processes the ratio of the ith rule's firing strength to the sum of all rule's firing strengths.

$$
\omega_{i}=\frac{\omega_{1}}{\omega_{1}+\omega_{2}}
$$

Layer 4: Each square node in this layer performs the function.

$$
O_{i}^{4}=\overline{\omega_{i}} f_{i}=\overline{\omega_{i}}\left(p_{i} x+q_{i} y+r_{i}\right)
$$

where $\left\{p_{i}, q_{i}, r_{i}\right\}$ is the parameter set referred as consequent parameters.

Layer 5: The unique node in this layer computes the overall summation of all incoming signals

$$
O_{i}^{5}=\sum_{i} \overline{\omega_{i}} f_{i}=\frac{\sum_{i} \omega_{i} f_{i}}{\sum_{i} \omega_{i}}
$$

The average percentage error is used as a criterion to evaluate both techniques:

$$
A P E=\frac{1}{p} \sum_{i=1}^{p} \frac{\left|T^{\prime}(i)-O(i)\right|}{|T(i)|} * 100 \%
$$

First of all, a fuzzy inference system with default membership functions and rule set is generated. Figure 5 (top) depicts the default membership functions for irradiance and temperature. It is observed that these functions are uniformly distributed over the data range (universe of discourse) for each input.

After training the network, premise and consequent parameters are adjusted according to the backpropagation error. Figure 5 (bottom) shows that membership functions for temperature have no significant changes, however, those of irradiance changed considerably, which confirm the high dependency of the maximal power on the irradiance.

Figure 6 (left) demonstrates the performance of tracking operation based on anfis. The right surface plot in Figure 6 is a surface indicating that the relationship between temperature, irradiance and maximal voltage is non-linear.

Experimental investigation of artificial intelligence applied in MPPT techniques (S. Della Krachai) 

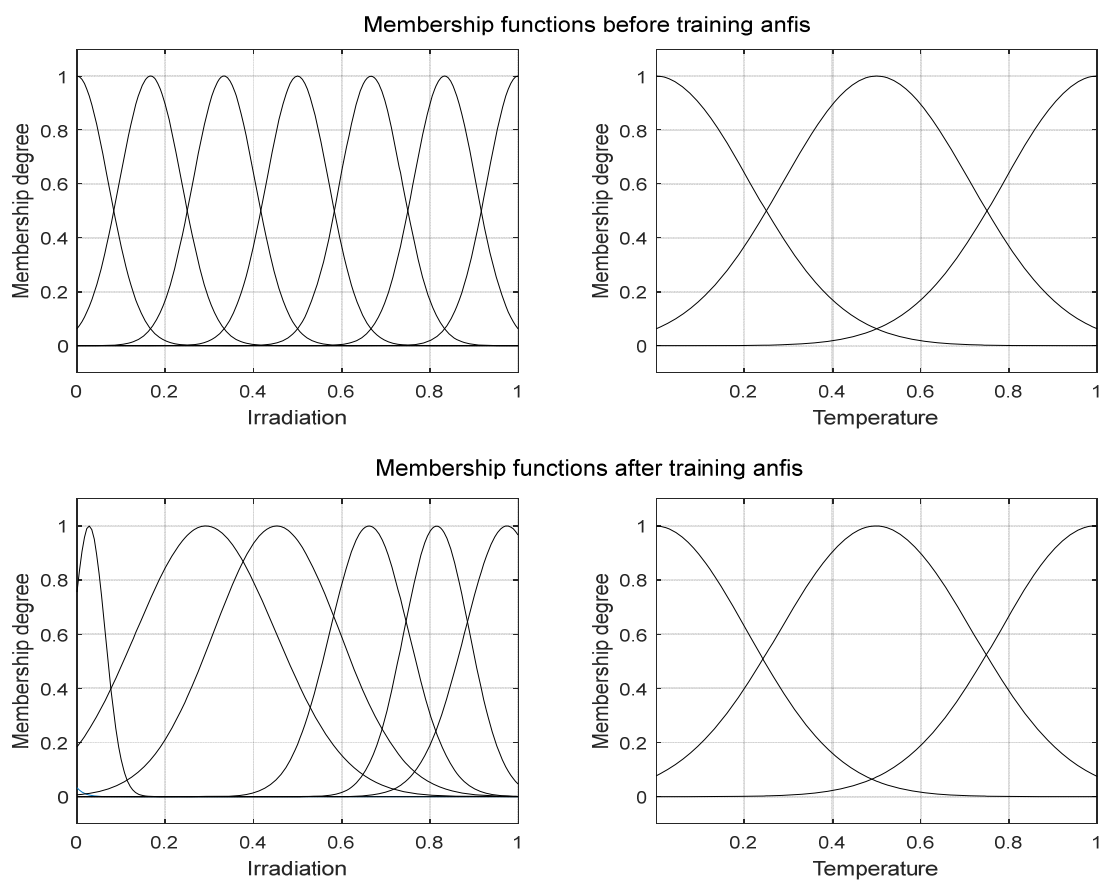

Figure 5. ANFIS membership functions before (top) and after (bottom) training
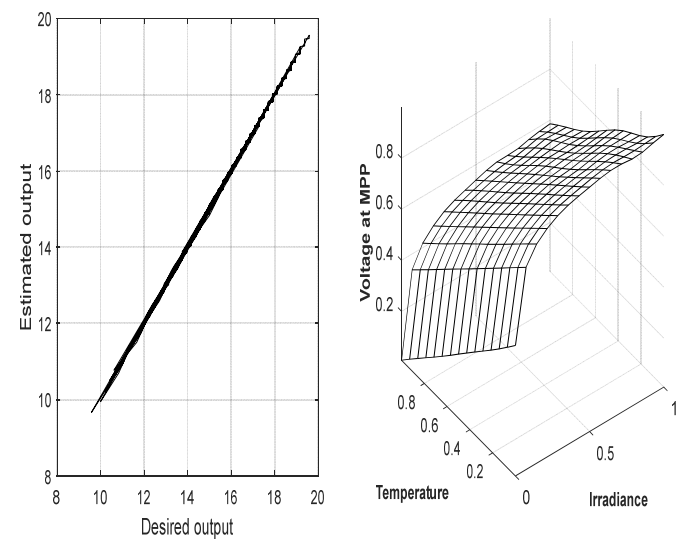

Figure 6. ANFIS learning process results

In order to connect the PV panels to the load, a power converter is used as a mean to transfer a regulated power from one side to the other.

\section{SYNCHRONOUS BUCK CONVERTER MODELING}

Synchronous buck converter is a step-down converter where the diode is replaced with a switch to minimize the losses due to the commutation in the off-time period of the main switch, thus improving the efficiency of the converter. The circuit is given by Figure 7, where the switch mosfet/2 replaces the diode in the conventional buck configuration.

The elements of the converter are sized correctly to meet the following requirements: a switching frequency of $200 \mathrm{khz}$, and a maximal output current of 10A. A PWM driver is used to drive the mosfets from the signal generated by a controller. 
We have used a PID controller to generate the duty cycle D needed to track the maximum voltage Vmpp. Tuning this PID controller is easy when the components values $\mathrm{L}$ and $\mathrm{C}$ are precisely known. However, manufacturers propose tolerances on their components (the inductor used WE-7443631000 is from Würth Elektronik with a tolerance of $\pm 15 \%$ ). The PID is tuned to take into account components tolerance of the buck converter to obtain high efficiency within the range of expected values for $\mathrm{L}$ and $\mathrm{C}$.

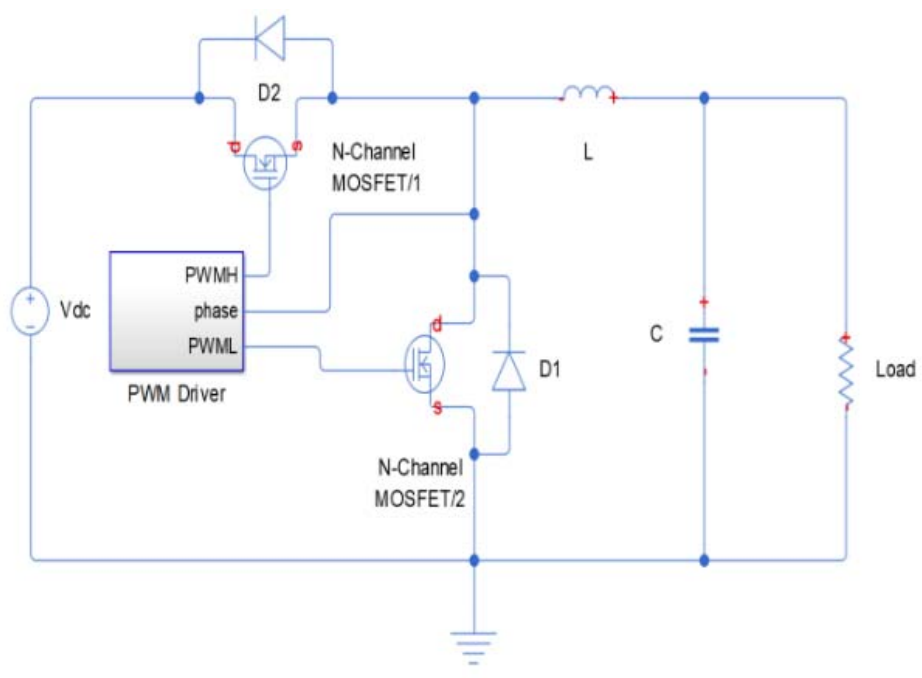

Figure 7. Synchronous buck converter topology

\section{SYSTEM SIMULATION}

Before deciding to implement the controller and the trackers, we have conducted a simulation considering changes in temperature and irradiance.

Neural networks are first simulated. From Figure 8, the system is left in idle mode until 0.05 second past. The tracking operation is engaged for an irradiance of $500 \mathrm{~W} / \mathrm{m}^{2}$ and temperature of $25^{\circ} \mathrm{C}$, the panel voltage (plot1 - red curve) follows precisely the maximal voltage computed by the neural network. An irradiance disturbance (an increase from $500 \mathrm{~W} / \mathrm{m}^{2}$ to $1000 \mathrm{~W} / \mathrm{m}^{2}$ ) is injected at the time $0.15 \mathrm{~s}$, the PID controller adjusts the duty cycle accordingly to keep tracking the maximal voltage. At time $0.22 \mathrm{~s}$, a temperature variation is introduced (an increase from $25^{\circ} \mathrm{C}$ to $40^{\circ} \mathrm{C}$ ). A small decrease in panel voltage is observed with no effect on the output current.

The fuzzy inference system issued from anfis training (Figure 9) tracks with high precision the maximal power generated from PV panel regardless environmental changes.

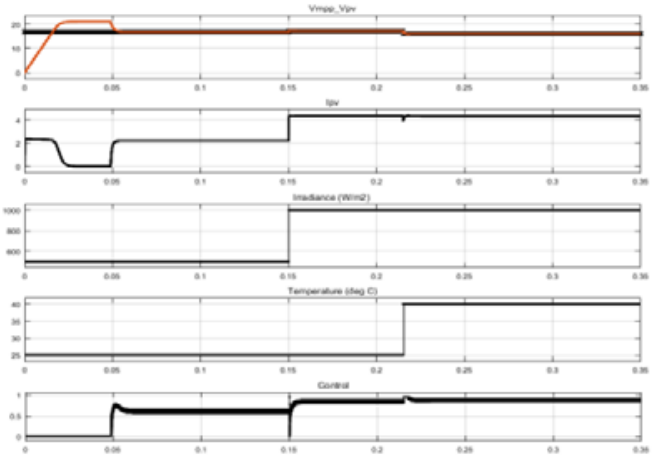

Figure 8. Neural networks maximal power tracking for irradiance and temperature variation

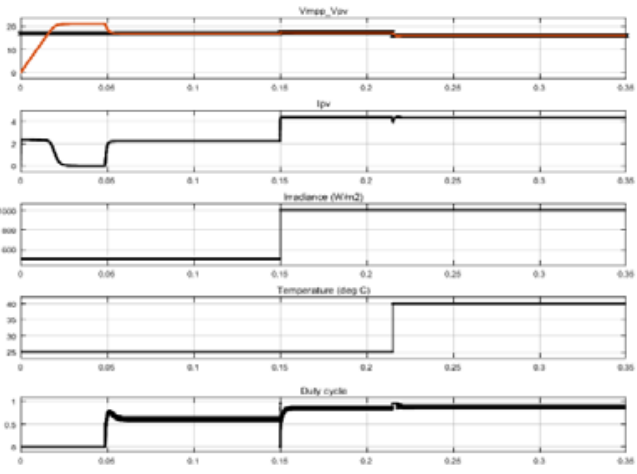

Figure 9. Fuzzy logic maximal power tracking for Irradiance and temperature variation 


\section{EXPERIMENTAL SETUP}

It is composed of two major circuits. A measurement circuit (Figure 11) and a power circuit (Figure 10(a)). The power circuit comprises the synchronous buck converter (two mosfets), the pwm driver IR2104 and also input/output curents/voltages measurements.

The measurement circuit is built essentially around two sensors attached to the PV panel. SP-110 irradiance sensor from apogee instruments, is used to capture solar irradiance with an output of $0.2 \mathrm{mV} /\left(\mathrm{W} / \mathrm{m}^{2}\right)$, which is amplified by an instrumentation amplifier AD620. The second sensor is the temperature sensor LM35 which produces $10 \mathrm{mV} /{ }^{\circ} \mathrm{C}$. Arduino based microcontroller is used as an embedded computing platform. The final PCB used in experimentation is given in Figure 10(b).

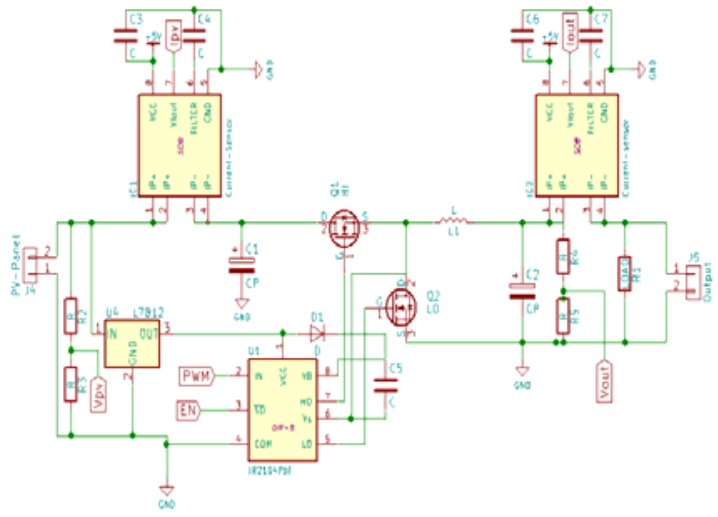

(a)

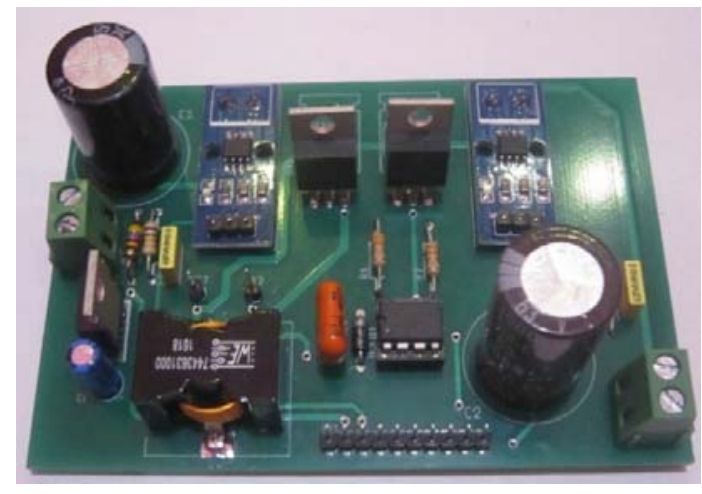

(b)

Figure 10. Synchronous buck converter power electronics

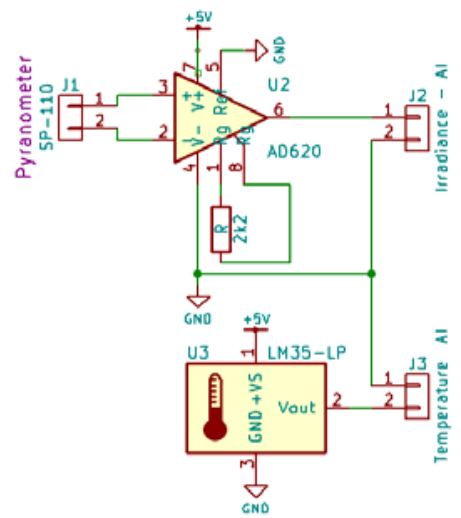

(a)

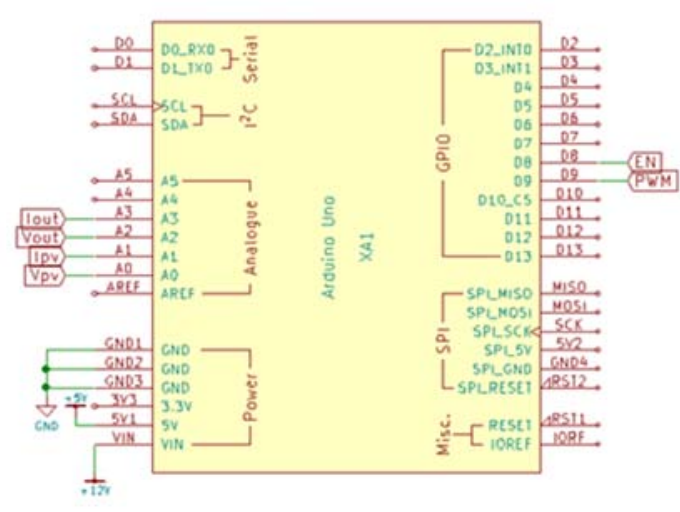

(b)

Figure 11. (a) Irradiance and temperature measurements circuit (b) Arduino interface

\section{HARDWARE-IN-THE-LOOP}

The software is implemented in Simulink using arduino platform as a target microcontroller. The information captured from sensors are first conditioned (amplified and filtered) to produce a high-fidelity image of the measures. This is the role of the signal conditioning block in Figure 12. The tracker (neural networks/fuzzy system) computes at its output the reference voltage $\left(\mathrm{V}_{\mathrm{mpp}}\right)$ at which the produced power is maximal.

This reference is then compared to the measured voltage at PV panel terminals. A PID controller designed and tuned to eliminate the error between reference and measured voltages, outputs a command signal which represents the variation on the duty cycle. A PWM generator receives the duty cycle and produces pulses which are fed to the IR2104 circuit driver to switch the mosfet transistors. 


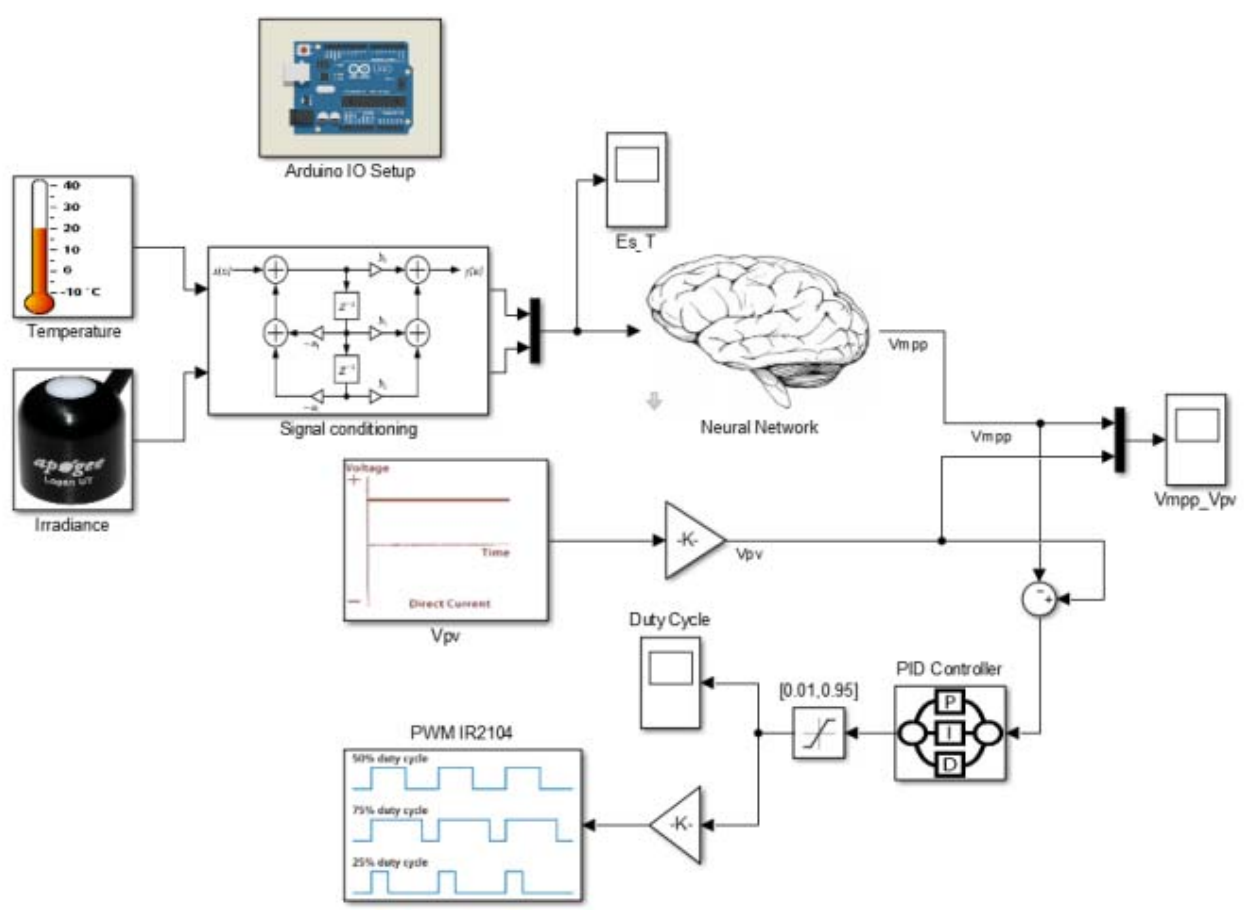

Figure 12. Hardware in the Loop implementation of the system

\section{EXPERIMENTAL RESULTS}

The PID outputs a duty cycle variation corresponding to tracking the maximal voltage generated by PV panel in environmental conditions given by Figure 13, which represents the real-time measurements of irradiance and temperature from the sensors for the day 05/19/2018 in Oran -Algeria.

Figure 14 confirms the tracking performance. It is shown that the PV panel voltage (blue curve) tracks precisely Vmpp (yellow curve) in the presence of fluctuations in irradiance and temperature.

Figure 15 shows that the panel have been exposed to a variation of irradiance due to the passage of clouds, while the temperature oscillate smoothly around $30^{\circ} \mathrm{C}$. For these conditions the neural network MPP controller succeeds to extract the maximal voltage from the PV panel (Figure 16).

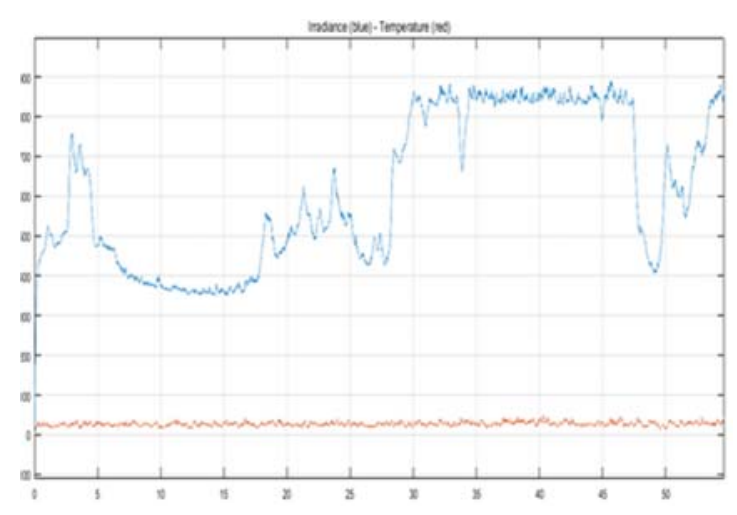

Figure 13. Real time irradiance(blue) and temperature(red) measurements

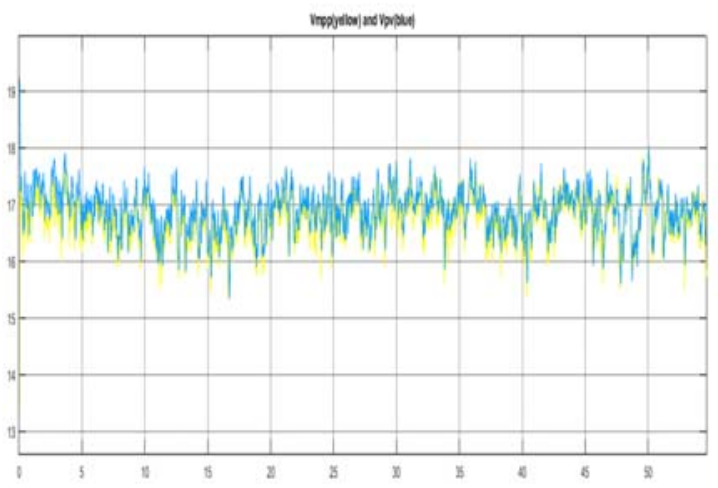

Figure 14. ANFIS MPP tracker results 


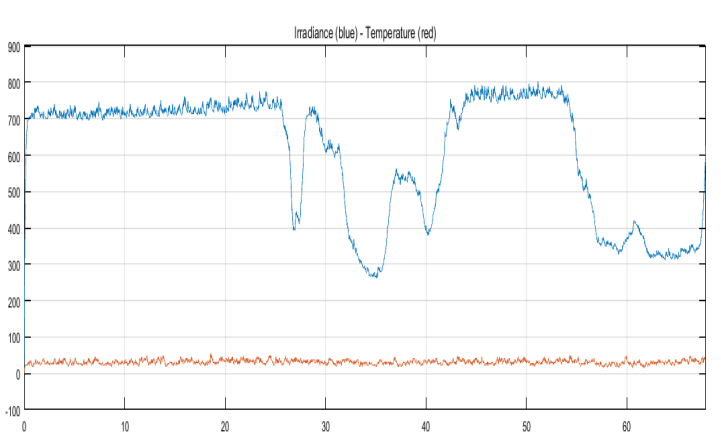

Figure 15. Real-time Irradiance and temperature measurements

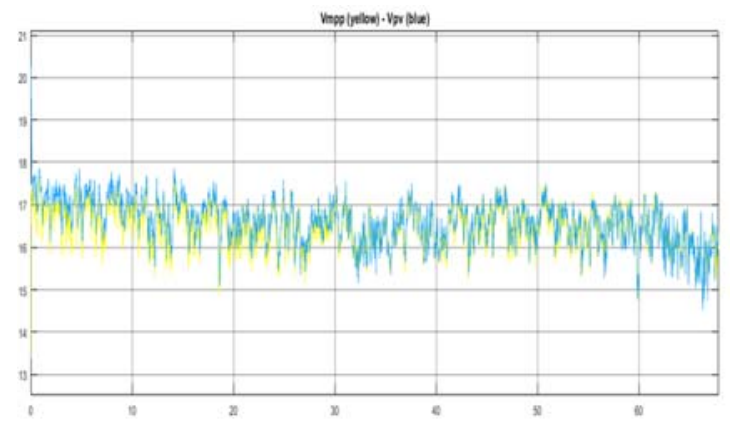

Figure 16. Tracking the MPP using neural neworks

Obtained results show that an efficiency of about $98 \%$ is ensured using the proposed techniques, as well as, the tracking operation is smooth and ensured. From experimental point of view, the results are also verified. Moreover, the proposed approach is based on a low-cost hardware (8bit microcontroller) which is programmed in a graphical block environment instead of hard coding. This gives the opportunity to tune the paramters inline (when running the system) in order to achieve best performances. The optimal obtained system, is then downloaded to the microcontroller to operate in a standalone mode.

\section{CONCLUSION}

In this paper, artificial intelligence is successfully applied in tracking the maximal power generated by PV panel. Neural networks and adaptive fuzzy inference systems, give promising results and satisfaction and can be both applied in tracking the MPP using a low-cost hardware.

Simulation results show the application of such techniques exhibits fast convergence regardless the variation of environmental conditions. On the other hands, experimental results prove the quality of such techniques in the efficiency improvement of the whole system.

\section{REFERENCES}

[1] TuffahaT.H., M. Babar, Y. Khan and N.H. Malik, "Comparative Study of Different Hill Climbing MPPT through Simulation and Experimental Test Bed," Research Journal of Applied Sciences, Engineering and Technology, vol. 7(20), pp. 4258-4263, 2014.

[2] Sheik, S.; Devaraj, D.; Imthias, T., "A novel hybrid Maximum Power Point Tracking Technique using Perturb\& Observe algorithm and Learning Automata for solar PV system," Energy, vol. 112, pp. 1096-1106, 2016.

[3] Luigi P., Renato R., Ivan S.andd Pietro T., "Optimized Adaptive Perturb and Observe Maximum Power Point Tracking Control for Photovoltaic Generation," Energies, vol. 8, pp. 3418-3436, 2015.

[4] Jubaer Ahmed, Zain al Salam, "An improved perturb and observe (P\&O) maximum power point tracking (MPPT) algorithm for higher efficiency," Applied Energy, vol. 150, pp. 97-108, 2015.

[5] HananeYatimi, Elhassan Aroudam, "MPPT algorithms based modeling and control for photovoltaic system under variable climatic conditions," Procedia Manufacturing, vol. 22, pp. 757-764, 2018.

[6] Chendi L., Yuanrui C., Dongbao Z., Junfeng L. and Jun Z., "A High-Performance Adaptive Incremental Conductance MPPT Algorithm forPhotovoltaic Systems," Energie, vol. 9, p. 288, 2016.

[7] Nabipour, M.; Razaz, M.; Seifossadat, S.; Mortazavi, S., "A new MPPT scheme based on a novel fuzzy approach," Renew. Sustain. Energy Rev, vol. 74, pp. 1147-1169, 2017.

[8] Della Krachai M., Midoun A., "High Efficiency Maximum Power Point Tracking Control inPotovoltaic-Grid Connected Plant," Acta Electrotechnica et Informatica, vol. 7, no. 1, 2007.

[9] Ravinder Kumar, Hari Om Bansal, "Real-time implementation of adaptive PV-integrated SAPF to enhance power quality," International Transactions On Electrical Energy Systems, 2019.

[10] Pradeep V., D., Hima, Bindu A. Divya, "Ant Colony Optimization basedMaximum Power Point Tracking (MPPT) for PartiallyShadedStandalone PV System," I J C T A, vol. 9(16), pp. 8125-8133, 2016.

[11] Yi-HuaLiu, Chun-LiangLiu, Jia-WeiHuang, Jing-HsiauChena, "Neural-network-based maximum power point tracking methods for photovoltaic systems operating under fast changing environments," Solar Energy, vol. 89, pp. 42-53, 2013.

[12] Rihab M. E., Mansour S., Hsan H. A., "Maximum Power Point Tracking Control Using Neural Networks for Stand-Alone Photovoltaic Systems," International Journal of Modern Nonlinear Theory and Application, vol. 3, pp. 53-65, 2014.

Int J Pow Elec \& Dri Syst Vol. 10, No. 4, Dec 2019 : 2138 - 2147 
[13] R. Kumar, P. Chaturvedi, H. O. Bansal and P. K. Ajmera, "Adaptive artificial neural network-based control strategy for shunt active power filter," 2016 International Conference on Electrical Power and Energy Systems (ICEPES), Bhopal, pp. 194-199, 2016.

[14] Ravinder Kumar, Hari Om Bansal, "Shunt active power filter: Current status of control techniques and its integration to renewable energy sources," Sustainable Cities and Society, vol. 42, pp. 574-592, 2018.

[15] Hornik K., Stinchcombe M., and White H., "Multilayer Feedforward Networks are Universal Approximators," Neural Networks, vol. 2, pp. 359-366, 1989.

[16] Marquardt, D., "An Algorithm for least-squares estimation of nonlinear parameters," SIAM Journal on Applied Mathematics, vol. 11, no. 2, pp.431-441, 1963.

[17] Chian-Song Chiu, "T-S Fuzzy Maximum Power Point Tracking Control of Solar Power Generation Systems," IEEE Trans Energy Conversion, vol. 25, no. 4, pp 1123-1132, 2010.

[18] Jyh-Shing Roger Jang, "ANFIS: Adaptive-Neural-Based Fuzzy Inference System," IEEE Transactions on Systems, Man, and cybernetics, vol. 23, no. 3, 1993.

\section{BIOGRAPHIES OF AUTHORS}

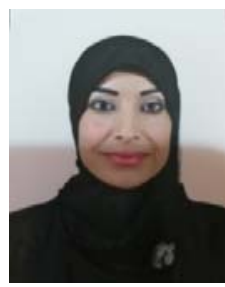

Phd student, University of Science and Technologies-Mohamed Boudiaf, Oran, Algeria, Electrical Engineering Faculty, Department of Electronics, e-mail: saidia.dellakrachai@univ-usto.dz .

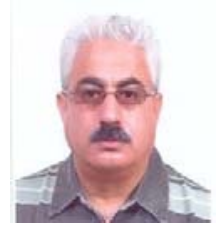

Research Director, University of Science and Technologies-Mohamed Boudiaf, Oran, Algeria, Electrical Engineering Faculty, Department of Electronics,

e-mail: Aboudghenes@gmail.com

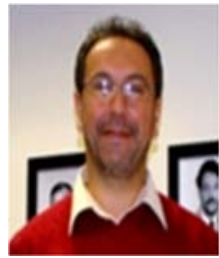

Dr, University of Science and Technologies-Mohamed Boudiaf, Oran, Algeria, Electrical Engineering Faculty, Department of Electronics, e-mail: mohamed.dellakrachai@univ-usto.dz

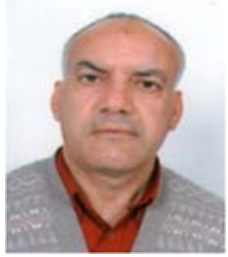

Dr, Spatial developement center, e-mail: M_bekhti@yahoo.fr 